\title{
COMPORTAMENTO DA LARANJEIRA PIRALIMA SOBRE Poncirus trifoliata COM VARIAÇÕES NA ALTURA DE ENXERTIA
}

\author{
V.R. SAMPAIO ${ }^{1}$ \\ Departamento de Horticultura - ESALQUSP - C.P. 9 - CEP: 13418-900 - Piracicaba,SP
}

\begin{abstract}
RESUMO: Pesquisou-se a combinação de laranjeira Piralima, Citrus sinensis (L.) Osb. sobre Poncirus trifoliata (L.) Raf. fazendo-se variaçōes nas alturas das enxertias, com operaçōes efetuadas a zero, dez, vinte e quarenta centímetros de altura. Avaliações realizadas após seis anos e meio de implantação do experimento permitiram as seguintes conclusōes: 1) as alturas das enxertias afetaram o desenvolvimento global das plantas, com as enxertias mais altas reforçando o efeito ananicante do Poncirus trifoliata; 2 ) as diferentes alturas de enxertia não afetaram as produções de frutos das três primeiras produçōes comerciais. Na quarta colheita surgiu diferença entre os tratamentos extremos, com maiores produçōes acontecendo para plantas enxertadas próximas ao solo; 3) o Poncirus trifoliata induziu características ananicantes as copas e as constantes boas produçōes de frutos de bom tamanho. Mostrou-se ser porta-enxerto interessante para o cultivar Piralima.
\end{abstract}

Descritores: laranja Piralima, Poncirus trifoliata, alturas de enxertia.

\section{BEHAVIOUR OF PIRALIMA ORANGE ON Poncirus trifoliata ROOTSTOCK AS A FUNCTION OF BUDDING HEIGHT}

\begin{abstract}
The combination Poncirus trifoliata $\mathbf{x}$ Piralima acidless orange was studied as a function of the budding height, from zero to forty centimeters. After six and half years of evaluations the results led to the following conclusions: 1) variation in the budding height affected the plant global development: the higher was the budding beight, the more intense was the Poncirus trifoliata dwarf effect. 2) variation in budding height did not affect orange yield during the first three commercial harvests. Difference occurred in the fourth harvest, between the extreme treatments, with larger yields for plants budded near to the soil. 3) Poncirus trifoliata induced dwarf characteristics to 'Piralima' stock as well as regular and good yield along the years, and the fruits were classified as high grade. Poncirus trifoliata showed to be an interesting rootstock for the cultivar Piralima.
\end{abstract}

Key Words: piralima acidless orange, Poncirus trifoliata, budding height.

\section{INTRODUÇÃO}

Segundo POMPEU JÚNIOR (1991), no planejamento de um pomar cítrico cuidados devem ser dispensados à escolha de copas e de portaenxertos, ambos sendo igualmente importantes $e$ não podendo ser modificados facilmente, como um programa de adubação ou um esquema de pulverização. Embora a citricultura brasileira esteja assentada sobre um único porta-enxerto, o limão Cravo, a pesquisa e a experimentação vem demonstrando que a utilização de outros portaenxertos, como as tangerineiras Cleopatra, Sunki e - Poncirus trifoliata permitem obter frutos de melhor qualidade e outras vantagens que podem resultar em benefícios financeiros ao produtor. Outro aspecto a ser considerado na escolha do porta-enxerto, baseia-se nas observações que o plantio semi-adensado pode gerar maiores produtividades, especialmente na primeira década de vida do pomar. Assim, o emprego de portaenxertos ananicantes, associado à copas de boas produtividades poderá ser altamente interessante, facilitando inclusive os tratos culturais.

FIGUEIREDO (1976) estudando o comportamento da laranjeira Barão, em dez portaenxertos, dentre outras conclusões fez a seguinte: "O aumento dos custos dos tratos culturais leva à recomendação de que em futuro próximo as plantas cítricas devam ser enxertadas em porta-

${ }^{1}$ Bolsista do CNPq, Professor Aposentado.

Sci. agric., Piracicaba, 51(1):69-74, jan./abr., 1994 
enxertos que induzam nanismo, de alta produtividade. Os dados obtidos no presente experimento permitem indicar o Poncirus trifoliata como o porta-enxerto que atenderia a essas condições.

Trabalho de TEÓFILO SOBRINHO (1972) enfocando o comportamento de laranjeira Valencia sobre nove porta-enxertos, verificou tendência a maiores produções por volume de copa para porta-enxertos com características ananicantes, ou seja, citrange Troyer, limão Rugoso da Florida, limão Rugoso Nacional e Poncirus trifoliata. Este último apresentou o menor volume de copa, frutos de boa qualidade e produção tardia.

A muda cítrica deve ter o enxerto realizado entre dez e vinte centímetros, segundo a Portaria 402 de 1980, BRASIL (1981). Essa norma está embasada nas recomendações dos técnicos, como é dado a verificar pelos trabalhos de MOREIRA \& SALIBE (1977), TEÓFILO SOBRINHO (1991) dentre outros.

De acordo com BITTERS et al. (1981) a altura ótima para enxertia das plantas cítricas, visando melhor comportamento no pomar, não foi ainda estabelecida. As alturas utilizadas pelos viveiristas dizem mais respeito á conveniência e a tradição. Na revisão feita por estes autores, ficou evidenciada que a altura de enxertia influencia $o$ comportamento da planta cítrica.

SALIBE et al. (1970) enxertaram laranja Baianinha nos porta-enxertos limão Cravo, laranja Caipira e Poncirus trifoliata nas alturas de zero, vinte e cinco e cinquenta centímetros a partir do colo. Após as seis primeiras safras, verificaram diminuição da produção em razão do aumento da altura de enxertia para o limão Cravo e o Poncirus trifoliata. Para laranja Caipira ocorreu o inverso. Assim também SALIBE \& MISCHAN (1981) observaram o comportamento da tangerineira Ponkan enxertada em limão Volkameriano, nas alturas de zero, vinte e cinco e cinquenta centímetros. Sete anos após o plantio anotaram que as produções acumuladas foram afetadas pelas diferentes alturas de enxertia.

BITTERS et al. (1981) analisaram o comportamento da laranjeira Valencia sobre a tangerineira Cleopatra e citrange Troyer, fazendo enxertias nas alturas de cinco, quinze, trinta, quarenta e cinco, sessenta e noventa centímetros. Após quatorze anos constataram que as maiores plantas e produções aconteceram para aquelas enxertadas a altura usual. A altura crítica da enxertia situar-se-ia a cerca de trinta centímetros.
Dentro da mesma linha de pesquisa, MOREIRA et al. (1981) realizaram observações com o cultivar Washington-Navel sobre os porta-enxertos limão Cravo, Laranja-Doce e Poncirus trifoliata fazendo enxertias a zero, vinte e cinco e cinquenta centímetros. Após dezesseis anos verificaram maiores desenvolvimentos para as plantas enxertadas ao nível do solo. Também MURRAY (1951), enxertando pomelo à diferentes alturas, entre cinco e sessenta e quatro centímetros, comprovou que quanto mais alta a enxertia, menores resultavam as plantas e as produções.

No presente experimento buscou-se informações sobre o comportamento da laranjeira Piralima quando enxertada em Poncirus trifoliata fazendo-se variações na altura de enxertia.

\section{MATERIAL E MÉTODOS}

O experimento foi desenvolvido no Departamento de Horticultura da Escola Superior de Agricultura "Luiz de Queiroz". As mudas experimentais foram obtidas iniciando-se com a semeação de Poncirus trifoliata cv. mexicano, em maio de 1983. As sementes foram fornecidas pela Estação Experimental de Cordeirópolis.

A 03-12-1984 procedeu-se a enxertia com borbulhas de 'Piralima', fazendo-se variações nas alturas da enxertia, as quais resultaram nos seguintes tratamentos:

1) Enxertia no colo dos porta-enxertos;

2) Enxertia a $10 \mathrm{~cm}$ do colo dos porta-enxertos;

3) Enxertia a $20 \mathrm{~cm}$ do colo dos porta-enxertos;

4) Enxertia a $40 \mathrm{~cm}$ do colo dos porta-enxertos.

As mudas de torrão foram arrancadas em 19-12-1985 e plantadas na mesma data, no espaçamento de $4.40 \times 5.50$ metros, em solo classificado como latossolo vermelho, série Luiz de Queiroz. A área, anteriormente ocupada com ameixeiras (Prunus salicina), havia sofrido subsolagem e gradeações.

Procedeu-se à adubação de cova com 600 gramas de superfosfato.

$O$ experimento foi delineado em blocos ao acaso com cinco repetições para os quatro tratamentos. A parcela constou de duas plantas.

$\mathrm{Na}$ condução do experimento, foram realizadas adubações e aplicações de calcário 
orientadas através da análise de solo, irrigações em períodos críticos e pulverizações que resultaram em bom estado geral das plantas. $O$ controle do mato foi realizado através de aplicação de herbicida (Glyphosate) na projeção da copa das plantas e roçagem do restante da área, recoberta por gramíneas.

Fez-se avaliação experimental através do acompanhamento do desenvolvimento e das produções das plantas. O volume da copa, determinado para o ano de 1992, foi calculado empregando-se a fórmula utilizada por POMPEU JR. (1972), $V=2 /{ }_{3} \pi r^{2} H$. Os resultados obtidos foram submetidos à análise estatística conforme delineamento empregado. Para comparação das médias empregou-se o teste de Tukey.

\section{RESULTADOS E DISCUSSÃO}

1. Desenvolvimento das Plantas: $\mathrm{Na}$ data de 0204-1992 foram efetuadas as mensurações das plantas experimentais. Assim foram medidas as circunferências dos troncos a quarenta e cinco centímetros do solo, os diâmetros e alturas das copas. Os resultados encontrados estão resumidos na TABELA 1.

Foram observadas maiores circunferências de troncos para plantas onde foram realizadas enxertias mais baixas. Assim os tratamentos um e dois, enxertias baixas, foram significativamente diferentes dos tratamentos três e quatro onde as enxertias foram feitas a vinte $e$ quarenta centímetros do colo das plantas. Considerando-se que a circunferência do tronco da planta é consequência do desenvolvimento global da mesma, infere-se que os enxertos à baixa altura favoreceram esse efeito. Este resultado é concordante com a literatura citada neste trabalho.

As alturas e volumes das copas das plantas então com seis anos e meio de idade, mostram o efeito ananicante do porta-enxerto Poncirus trifoliata, pois segundo a FIGUEIREDO (1991) o cultivar Piralima caracteriza-se por produzir árvores de médio a grande porte. Este efeito comprova as informações de FIGUEIREDO (1976) e TEÓFILO SOBRINHO (1972). Observase para o parâmetro volume de copa praticamente a repetição de análise feita para circunferência do tronco. Enxertias mais baixas propiciaram plantas com maior volume de copa, sendo que os tratamentos um e dois foram significativamente diferentes do tratamento quatro. Para altura das plantas a análise não revelou diferença significativa entre os tratamentos, embora tenha se observado tendência de redução de porte com a elevação da altura de enxertia.

As projeções das copas das plantas determinaram áreas de $5.47,5.47,4.52$ e $4.22 \mathrm{~m}^{2}$ para os tratamentos um, dois, três e quatro respectivamente, para plantas com seis anos e meio de idade. Os diâmetros médios destas projeções foram respectivamente $2.65,2.64,2.41$ e 2.33 metros. Estes números mostram que as copas das plantas ainda guardavam certa distância entre si, pois o espaçamento empregado foi de $4.40 \times 5.50$ metros.

\section{Produção das Plantas}

2.1. Número de Frutos: As plantas iniciaram pequena produção em 1988, cerca de 28 meses após o plantio. Desde então os frutos foram colhidos e contados anualmente, $e$ os dados submetidos a análise usando-se transformação das observações para $\sqrt{ } x+0.5$. Os resultados experimentais estão na TABELA 2.

Pelo exame dos dados constata-se que não houve diferença entre os tratamentos para as produções de 88, 89, 90 e 1991, mas ocorreu para a produção de 1992, onde o tratamento um diferiu estatisticamente do tratamento quatro. Este resultado é explicado pelos diferentes volumes de copas existentes entre os dois tratamentos e provavelmente deverá persistir nas próximas colheitas.

2.2. Peso médio dos frutos: $O$ peso médio dos frutos foi determinado para os anos 90, 91 e 92, fazendo-se amostragem, na colheita, de trinta frutos por árvore. Os resultados estão na TABELA 3.

Verifica-se inexistência de diferença de peso entre os frutos em função dos tratamentos utilizados. O peso médio geral foi de $125,5 \mathrm{~g}$. Este valor está acima do peso médio do fruto deste cultivar, estimado como sendo de 110.0 gramas (FIGUEIREDO 1991).

2.3. Peso da produção por planta: Esta projeção foi realizada para os anos $89,90,91$ e 92 , ou sejam primeira, segunda, terceira e quarta produções comerciais, considerando-se desprezível a produção de 1988 , segundo ano de vida do pomar. Os resultados obtidos estão na TABELA 4.

Sabendo-se que $O$ experimento foi plantado em dezembro de 1985 , a produção de 1989, colhida no mês de abril, ocorreu em plantas com quarenta meses de implantação no campo. 
TABELA 1 - Média das circunferências dos troncos, das alturas e dos volumes das copas de laranjeiras Piralima enxertadas à diferentes alturas em Poncirus trifoliata. Piracicaba, 1992.

\begin{tabular}{lccc}
\hline Tratamentos & Circunferências & Altura das plantas & Volume das copas \\
& $(\mathrm{cm})$ & $(\mathrm{m})$ & $\left(\mathrm{m}^{3}\right)$ \\
\hline 1. Enxertia no colo & $25.92 \mathrm{a}$ & $2.94 \mathrm{a}$ & $10.90 \mathrm{a}$ \\
2. Enxertia a $10 \mathrm{~cm}$ & $25.34 \mathrm{a}$ & $2.95 \mathrm{a}$ & $11.07 \mathrm{a}$ \\
3. Enxertia a $20 \mathrm{~cm}$ & $23.08 \mathrm{~b}$ & $2.79 \mathrm{a}$ & $8.79 \mathrm{ab}$ \\
4. Enxertia a $40 \mathrm{~cm}$ & $22.76 \mathrm{~b}$ & $2.58 \mathrm{a}$ & $7.51 \mathrm{~b}$ \\
\hline \hline
\end{tabular}

${ }^{1}$ Médias seguidas da mesma letra, indicam não haver diferença significativa a nível de $5 \%$.

TABELA 2 - Número médio de frutos produzidos por laranjeiras Piralima enxertadas à diferentes alturas em Poncirus trifoliata. Piracicaba, 1992.

\begin{tabular}{lcccccc}
\hline \hline & \multicolumn{5}{c}{ Número médio de frutos por planta } \\
\cline { 2 - 7 } & \multicolumn{5}{c}{ Anos } \\
Tratamentos & $88^{\prime}$ & $89^{\prime}$ & $90^{\prime}$ & $91^{\prime}$ & $92^{\prime}$ & Totais $^{\mathrm{l}}$ \\
\hline Enxertia no colo & $2.6 \mathrm{a}$ & $189.1 \mathrm{a}$ & $509.6 \mathrm{a}$ & $520.7 \mathrm{a}$ & $566.4 \mathrm{a}$ & $1.788 .1 \mathrm{a}$ \\
Enxertia a $10 \mathrm{~cm}$ & $13.2 \mathrm{a}$ & $142.2 \mathrm{a}$ & $496.6 \mathrm{a}$ & $455.3 \mathrm{a}$ & $516.7 \mathrm{ab}$ & $1.573 .0 \mathrm{a}$ \\
Enxertia a $20 \mathrm{~cm}$ & $14.5 \mathrm{a}$ & $196.5 \mathrm{a}$ & $402.5 \mathrm{a}$ & $491.9 \mathrm{a}$ & $552.2 \mathrm{ab}$ & $1.657 .6 \mathrm{a}$ \\
Enxertia a $40 \mathrm{~cm}$ & $12.0 \mathrm{a}$ & $209.7 \mathrm{a}$ & $410.4 \mathrm{a}$ & $427.7 \mathrm{a}$ & $455.3 \mathrm{~b}$ & $1.515 .1 \mathrm{a}$ \\
\hline \hline
\end{tabular}

${ }^{1}$ Médias seguidas da mesma letra, indicam não haver diferença significativa a nível de $5 \%$.

TABELA 3 - Peso médio dos frutos de laranjeiras Piralima enxertadas à diferentes alturas em Poncirus trifoliata. Piracicaba, 1992.

\begin{tabular}{lcccc}
\hline \hline & \multicolumn{4}{c}{ Peso médio dos frutos $(\mathrm{g})$} \\
\cline { 2 - 5 } Tratamentos & $90^{1}$ & $91^{1}$ & $92^{1}$ & Médias \\
\hline Enxertia no colo & $116.6 \mathrm{a}$ & $126.7 \mathrm{a}$ & $137.3 \mathrm{a}$ & 123.5 \\
Enxertia a $10 \mathrm{~cm}$ & $116.2 \mathrm{a}$ & $127.6 \mathrm{a}$ & $142.5 \mathrm{a}$ & 128.7 \\
Enxertia a $20 \mathrm{~cm}$ & $115.9 \mathrm{a}$ & $127.4 \mathrm{a}$ & $136.3 \mathrm{a}$ & 126.5 \\
Enxertia a $40 \mathrm{~cm}$ & $118.2 \mathrm{a}$ & $118.9 \mathrm{a}$ & $133.0 \mathrm{~b}$ & 123.4 \\
\hline \hline
\end{tabular}

\footnotetext{
${ }^{1}$ Médias seguidas da mesma letra, indicam não haver diferença significativa a nível de $5 \%$.
} 
TABELA 4 - Produção em peso de laranjeiras Piralima enxertadas à diferentes alturas em Poncirus trifoliata. Piracicaba, 1992.

\begin{tabular}{lcccc}
\hline \hline & \multicolumn{5}{c}{ Peso médio dos frutos $(\mathrm{g})$} \\
\cline { 2 - 5 } Tratamentos & 89 & 90 & 91 & 92 \\
\hline Enxertia no colo & 23.73 & 59.42 & 65.45 & 77.76 \\
Enxertia a $10 \mathrm{~cm}$ & 17.84 & 51.89 & 58.09 & 73.62 \\
Enxertia a $20 \mathrm{~cm}$ & 24.66 & 46.64 & 67.04 & 75.26 \\
Enxertia a $40 \mathrm{~cm}$ & 26.31 & 48.50 & 50.85 & 60.55 \\
\hline Médias & 23.13 & 51.36 & 60.35 & 71.80 \\
\hline \hline
\end{tabular}

As produções são bem interessantes, principalmente tendo em vista as pequenas áreas ocupadas pelas plantas. FIGUEIREDO (1976) trabalhando com copa de 'Barão' enxertada em Poncirus trifoliata anotou valores de 14.11, 30.40, $52.04,58.38,59.95,85.78$ e 71.54 quilogramas para produções a partir do quarto ano de vida do pomar.

\section{CONCLUSÕES}

1. O porta-enxerto Poncirus trifoliala mostrou ser porta-enxerto interessante para o cultivar Piralima, induzindo as plantas à características ananicantes com constantes boas produções de frutos de bom tamanho.

2. Dentro dos limites estudados, as alturas das enxertias afetaram os desenvolvimentos globais das plantas. Enxertias mais altas reforçaram o efeito ananicante do porta-enxerto Poncirus trifoliata.

3. As diferentes alturas de enxertia não afetaram as produções de frutos das três primeiras produções comerciais. Na quarta colheita surgiu diferença entre os tratamentos extremos, com maiores produções acontecendo para plantas enxertadas próximas ao solo.

\section{REFERÊNCIAS BIBLIOGRÁFICAS}

BITTERS, W.P.; COLE, D.A.; MC CARTY, C.C. Effect of budding height on yield and tree size of 'Valencia' orange on two rootstock. In: INTERNATIONAL CITRUS CONGRESS, 1981, Tokyo, Proceedings... Tokyo: International Society of Citriculture, 1981. v.1, p. 109-110.

FIGUEIREDO, J.O. Comportamento da laranjeira-Barāo Citrus sinensis (L.) Osbeck, clone nucelar, em dez porta-enxertos. Campinas, 1976. 119p. Tese (Doutorado) - Universidade Estadual de Campinas.

FIGUEIREDO, J.O. Variedades copa de valor comercial. In: RODRIGUEZ, O.; VIEGAS, F.; POMPEU JUNIOR, J.; AMARO, A.A. Citricultura brasileira. Campinas, Fundação Cargill, 1991. v.1, p.229-264.

BRASIL. Ministério da Agricultura. Secretaria da Produção Vegetal. Legislação da inspeção e fiscalização da produção e do comércio de sementes e mudas. Brasília, 1981. 194 p.

MOREIRA, C.S.; RODRIGUEZ, O.; POMPEU JUNIOR, J.; TEÓFILO SOBRINHO, J.; SALIBE, A.A. The effect of budding heights on tree size of Citrus trees affected by exocortis viroid. In: INTERNATIONAL CITRUS CONGRESS, 1981, Tokyo, Proceedings... Tokyo: International Society of Citriculture. 1981. v.1, p. 148-149. 
MOREIRA, S.; SALIBE, A.A. Current citrus nursery pratices in Brazil. In: INTERNATIONAL CITRUS CONGRESS, 1977, Lake Alfred, Proceedings... Lake Alfred: International Society of Citriculture. 1977. v.1, p. 127-128.

MURRAY, D.B. Citrus experiments at the St. Augustine Experiment Station. Tropical Agriculture, Trinidad, v.28, p.215-217, 1951.

POMPEU JUNIOR, J. Estudo de comportamento de clones nucelares e velhos de laranjeira-Hamlin (Citrus sinensis L. Osbeck) em dois porta-enxertos. Piracicaba, 1972. 77 p. (Tese) Doutorado - Escola Superior de Agricultura "Luiz de Queiroz"/ Universidade de São Paulo.

POMPEU JUNIOR, J. Porta-enxertos. In: RODRIGUEZ, O.; VIEGAS, F.; POMPEU JUNIOR, J.; AMARO, A.A. Citricultura brasileira. Campinas: Fundação Cargill, 1991, v.1, p.265-280.

SALIBE, A.A.; RODRIGUEZ, O.; MOREIRA, S. Efeito da altura de enxertia no vigor e produtividade de laranjeiras baianinha. REUNIĀO ANUAL DA SOCIEDADE BRASILEIRA PARA O PROGRESSO DA CIÊNCIA, 22., Salvador. Resumos... Salvador: SBPC, 1970. p.209.
SALIBE, A.A.; MISCHAN, M.M. Effect of height of budding on vigor and productivity of Ponkan Mandarin trees. In: INTERNATIONAL CITRUS CONGRESS, 1981, Tokyo, Proceedings... Tokyo: International Society of Citriculture. 1981. v.1, p. 15.

TEÓFILO SOBRINHO, J. Comportamento da laranjeira Valencia, C.sinensis (L.) Osb. sobre diferentes portaenxertos. Piracicaba, 1972. 71 p. (Tese) Doutorado - Escola Superior de Agricultura "Luiz de Queiróz"/ Universidade de São Paulo.

TEÓFILO SOBRINHO, J. Propagação dos citros. In: RODRIGUEZ, O.; VIEGAS, F.; POMPEU JUNIOR, J.; AMARO, A.A. Citricultura brasileira. Campinas, Fundação Cargill, 1991. v.1, p.281-301.

Enviado para publicação em 25.04 .93

Aceito para publicação em 12.12 .93 